\section{Remedial Effects of Homeopathic Medicine in Chronic Suppurative Otitis Media-Related Complications}

\author{
Nazmul Hasan', Nazmul Ahsan', Ahmed Faisal Sumit', Latiful Bari² and \\ Anwarul Azim Akhand' \\ ${ }^{1}$ Departemnt of Genetic Engineering and Biotechnology, University of Dhaka, Dhaka-1000, \\ Bangladesh \\ ${ }^{2}$ Center for Advanced Research in Sciences, University of Dhaka, Dhaka-1000, Bangladesh
}

Bioresearch Communications

Volume 7, Issue 2, July 2021

DOI:

https://doi.org/10.3329/brc.v7i2.54372

\begin{abstract}
Chronic Suppurative Otitis Media (CSOM) is characterized by persistent otorrhoea from the middle ear through a perforated tympanic membrane. It is regarded as one of the most important causes of hearing impairment in developing countries. In many cases, treating CSOM with antibiotics generates fears of resistance. Unlike conventional antibiotics, homeopathic remedies are mostly free from side effects. Therefore, this study was performed to evaluate the effects of homeopathic medicines to treat CSOM patients. A total of 90 subjects were included in this study; among them, 60 were suffering from CSOM, and 30 were healthy controls. The CSOM patients were randomly assigned for the daily administration of homeopathic medicines such as tellurium metallicum in 6 C potency $(n=17)$, mercurius solubilis in $200 \mathrm{C}$ potency ( $n=13)$, and calcarea sulphurica in $30 \mathrm{C}$ potency $(n=10)$ for 8 weeks. Ear suppuration was prevented in all of the patients treated with the medicines. More than $50 \%$ of the patients' tympanic membrane perforation were healed by tellurium metallicum and calcarea sulphurica, however, no membrane healing was observed by mercuris solubilis. It was next examined whether the patients underwent hearing impairment compared to healthy control subjects. The average hearing thresholds of the control subjects $(n=30)$ at $1,4,8$, and $12 \mathrm{kHz}$ frequencies were $13.55 \pm 1.57,15.58 \pm 1.12,27.58 \pm 2.00$, and $32.57 \pm 2.45$ $\mathrm{dB}$ SPL, respectively. When the average hearing thresholds of the CSOM patients $(n=40)$ were measured at all of the above frequencies, the values became $30.25 \pm 1.75,36.80 \pm 3.25,50.75 \pm 2.35$, and $59.50 \pm 2.96 \mathrm{~dB} \mathrm{SPL}$, respectively. This result indicated the loss of hearing in CSOM patients as the average hearing thresholds of the patients were significantly higher $(p<0.05)$ than that of the control subjects. Treatment for 8 weeks with all three homeopathic medicines significantly reduced $(p<0.05)$ hearing thresholds of the patients at all the frequencies. This result demonstrated dramatic improvement in patients' hearing by the homeopathic medicines. This study, therefore, provides conclusive evidence that homeopathic medicines prevent ear suppuration in CSOM patients as well as heal perforated membrane, and improve hearing.
\end{abstract}

KEYWORDS: Chronic Suppurative otitis media, Ear suppuration, Tympanic membrane perforation, Hearing loss, Homeopathic medicine.

RECEIVED: 17 March 2021, ACCEPTED: 08 June 2021

TYPE: Original Research
CORRESPONDING AUTHOR: Anwarul Azim Akhand, Department of Genetic Engineering and Biotechnology, University of Dhaka, Dhaka-1000.

Email: akhand@du.ac.bd

\section{Introduction}

Chronic Suppurative Otitis Media(CSOM) is an infectious disease characterized by the persistent discharge from the middle ear through a perforated tympanic membrane (Smith et al., 2010). CSOM is considered as one of the most common causes of hearing impairment and disability in developing countries. The prevalence of CSOM is 65 to 330 million people worldwide, and $60 \%$ of them significantly suffer from hearing impairment (Morris, 2012). The incidence of CSOM is similar in children and adults (Morris, 2012), and a high incidence is observed in developing countries than in the other regions (Schilder et al., 2016). In developing countries poverty, overcrowded unhygienic living conditions, family history, smoking habit, etc. let people live in a condition favorable for infection to occur more frequently (Lasisi et al., 2007, Koch et al., 2011, Fliss et al., 1991). CSOM and its associated complications are demonstrated in various studies. CSOM is the most frequent cause of mild to moderate hearing impairment among children in Africa, Brazil (Muya and Owino, 1986, Bastos, 1996), India (Jacob et al., 1997), Sierra Leone (Seely et al., 1995), Thailand (Antarasena et al., 1988), and Norway (Aarhus et al., 2015).
In Bangladesh, a nationwide survey on CSOM is not available. The recurrence and length of sufferings in children and adults are very common (Talukder et al., 2016). Pathogenic microorganism-induced CSOM is one of the major cause of conductive type hearing impairment where sound wave fails to reach and convert into mechanical energy due to lack of communication among the tympanic membrane, ear bones, and the cochlea (Schilder et al., 2017). Another type of hearing impairment is sensorineural, where converted sound energy fails to convey into the brain due to auditory nerve complaints (Zahnert, 2011).

It is usually hard to cure CSOM with antibiotics as most of the most common infecting organisms are often resistant to them (Gehanno and Group, 1997). The treatment of such cases may even need surgical intervention. Therefore, improvement of hearing loss due to CSOM is difficult by conventional medicines, and these medicines are less effective in healing tympanic membrane perforation (Zahnert, 2011, Sinkkonen et al., 2014). In this study, we, for the first time evaluated the effects of homeopathic medicines for remedies of the CSOM 
symptoms, healing of tympanic membrane perforation, and improvement of hearing impairment.

\section{Materials and Methods}

\section{Study subjects}

In this study, 90 subjects of different ages of both sexes were included. Among them, 60 were suffering from CSOM, where 40 individuals were included as the treatment group and 20 were as a disease control (placebo) group. The remaining 30 were healthy controls. This study was conducted in Dhaka,
Bangladesh. Ethical issues were considered for conducting this study. The study was approved by the Ethical Review Committee of the Faculty of Biological Sciences, University of Dhaka (Ref no. 55/BioSci/2017-2018). All of the participating subjects went through two tests- capturing the images of the tympanic membrane using a digital endoscopic otoscope, and measuring the hearing thresholds. A flowchart representing the overall study is included below:

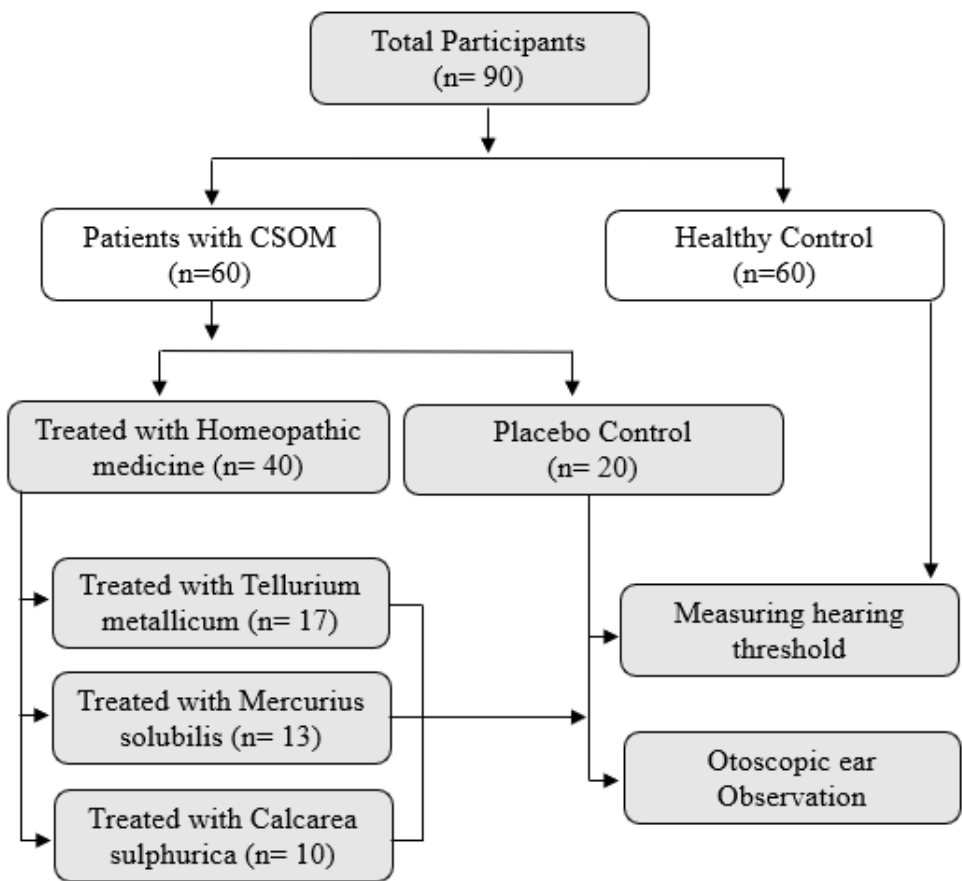

Patients who were taking antibiotics and who underwent ear surgery were not included in this study. The treated patients were grouped according to the homeopathic medicines they have been prescribed to take for 8 weeks (Table-1).

Table 1. Selective characteristics of the CSOM patients

\begin{tabular}{ccl}
\hline Group & $\begin{array}{c}\text { No. of patients } \\
\text { treated }\end{array}$ & \multicolumn{1}{c}{ Inclusion Characteristics } \\
\hline $\begin{array}{c}\text { Tellurium metalicum } \\
(\mathrm{TM})\end{array}$ & 17 & $\begin{array}{l}\text { CSOM with constant pus with pungent or garlicky odor } \\
\text { Tympanic membrane perforation } \\
\text { Hearing impairment }\end{array}$ \\
\hline $\begin{array}{c}\text { Mercurius solubilis } \\
(\mathrm{MS})\end{array}$ & 13 & $\begin{array}{l}\text { CSOM with yellow thick pus } \\
\text { Pain with suppuration in the eardrum and Eustachian tube } \\
\text { Hearing impairment with tinnitus, better on deglutition }\end{array}$ \\
\hline $\begin{array}{c}\text { Calcarea sulphurica } \\
(\mathrm{CS})\end{array}$ & 10 & $\begin{array}{l}\text { CSOM with greenish-yellow in color pus } \\
\text { Occasional balance issue with tinnitus } \\
\text { Hearing impairment with a slow tendency to heal }\end{array}$ \\
\hline
\end{tabular}


In TM group, $0.5 \mathrm{ml}$ Tellurium metallicum $6 \mathrm{C}$ was dissolved in $60.0 \mathrm{ml}$ distilled water, and the patients were advised to take orally $2 \mathrm{ml} / 24 \mathrm{hrs}$ before meals for 4 weeks. The healing of the ruptured tympanic membrane was assayed followed by measuring the hearing threshold level. They were given the same medicine and the same dose for the next 4 weeks. In the case of MS group, Mercurius solubilis $(0.5 \mathrm{ml}$ of $200 \mathrm{C}$ potency) was added in $60 \mathrm{ml}$ distilled water and was prescribed. And for the CS group, the Calcarea sulphurica (0.5 $\mathrm{ml}$ of 30C potency) was mixed with $60 \mathrm{ml}$ distilled water and was prescribed. The duration and dose of MS and CS group were similar as described for the TM group.

\section{Otoscopic ear observation}

The study subject's ear canal and tympanic membrane were examined aseptically with a digital endoscopic otoscope (Blueskysea, Guangdong-China), and images were captured every two weeks till the end of the eight weeks of treatment.

\section{Measuring hearing thresholds}

The patients' audiometric examination was conducted in a sound-proof room using an iPod with earphones as previously describes (Sumit et al., 2015; Das et al., 2018). The hearing level was measured at $1,4,8$ and $12 \mathrm{kHz}$ frequencies for the participating subjects. They were provided an initial 5 decibel (dB) stimulus followed by a stepwise increase in sound level by $5 \mathrm{~dB}$. For conforming the reproducibility of the results, examinations were duplicated for each of the subjects. The subjects were categorized as low/mild hearing loss if the average of the pure-tone threshold is higher than $20 \mathrm{~dB}$ SPL, at 1 and $4 \mathrm{kHz}$ frequencies. Extra high-frequency hearing loss was considered if the average threshold was found higher than $40 \mathrm{~dB}$ SPL, at 8 and $12 \mathrm{kHz}$ frequencies.

\section{Results}

\section{Characteristics of the study participants}

In this study, we included 90 subjects, where $30(33.33 \%)$ were healthy control, $20(22.22 \%)$ were placebo control and $40(44.44 \%)$ were patients treated with homeopathic medicines (Table-2). The number of male and female participants were $54(60 \%)$ and $36(40 \%)$, respectively. Among the male participants, $18(33.33 \%)$ were in the control group, 12 (22.22\%) were in placebo control, and 24 (44.44\%) in the treated group; and among the female participants, 12 $(33.33 \%)$ were in control, $8(22.22 \%)$ were in placebo control and $16(44.44 \%)$ in the treated group. The average age of males and females was $34.96 \pm 2.66$ and $28.25 \pm 2.33$ years, respectively. The mean body mass index (BMI) of all participants was $24.41 \pm 0.69$, and for control and treated groups, it was $25.46 \pm 0.92$ and $24.13 \pm 0.82$, respectively. The participating subjects were further categorized as under-, normal- and over-weight based on their BMI value of $<18.5$, $18.5-25$, and $>25 \mathrm{~kg} / \mathrm{m}^{2}$, respectively. Among the $60 \mathrm{CSOM}$ patients, $11(18.33 \%)$ were suffering from the disease for $\leq 2$ years, and the remaining $49(81.66 \%)$ for $>2$ years.

Table 2. Characteristics of the study participants

\begin{tabular}{|c|c|c|c|c|}
\hline \multirow{2}{*}{ Variable } & \multirow{2}{*}{ Participants } & \multicolumn{2}{|c|}{ Control } & \multirow{2}{*}{$\begin{array}{l}\text { Treated } \\
\text { patient }\end{array}$} \\
\hline & & Healthy & Patient & \\
\hline Total No. & 90 & $30(33.33 \%)$ & $20(22.22 \%)$ & $40(44.44 \%)$ \\
\hline \multicolumn{5}{|l|}{ Gender } \\
\hline$\overline{\text { Male: } \mathrm{n}(\%)}$ & $54(60 \%)$ & $18(60 \%)$ & $12(60 \%)$ & $24(60 \%)$ \\
\hline Female: $\mathrm{n}(\%)$ & $36(40 \%)$ & $12(40 \%)$ & $8(40 \%)$ & $16(40 \%)$ \\
\hline \multicolumn{5}{|l|}{ Age } \\
\hline$\overline{\text { Male }}$ & $34.96 \pm 2.66$ & & & \\
\hline Female & $28.25 \pm 2.33$ & & & \\
\hline BMI Kg/m² (Mean \pm S.E) & $24.41 \pm 0.69$ & $25.46 \pm 0.92$ & $24.91 \pm 0.62$ & $24.13 \pm 0.82$ \\
\hline \multicolumn{5}{|l|}{ BMI category* } \\
\hline Underweight & $6(6.66 \%)$ & - & $2(10 \%)$ & $4(10 \%)$ \\
\hline Normal weight & $38(42.22 \%)$ & $22(73.33 \%)$ & $11(55 \%)$ & $19(47.5 \%)$ \\
\hline Overweight & $46(51.11 \%)$ & $8(26.66 \%)$ & $7(35 \%)$ & $17(42.5 \%)$ \\
\hline \multicolumn{5}{|l|}{ Duration of Disease } \\
\hline$\leq 2$ years & - & - & $3(15 \%)$ & $8(20 \%)$ \\
\hline$>2$ years & - & - & $17(85 \%)$ & $32(80 \%)$ \\
\hline
\end{tabular}

* The subjects were categorized as underweight, normal weight and overweight when the BMI was found $<18.5,18.5-25$, and $>25 \mathrm{~kg} / \mathrm{m} 2$, respectively

Effects of medicines in ear suppuration and healing of membrane perforation
Discharge from the middle ear and perforation of the tympanic membrane mainly occurs due to chronic inflammation associated with CSOM. Therefore, the ear canals of the 
CSOM patients were examined using an otoscope to observe any structural changes/perforation of the tympanic membrane associated with middle ear effusion. Seventeen (17) patients suffering from CSOM were given Tellurium metallicum and their ear canals were examined every 4 weeks (Table 3 ). Invariably all the patients were experiencing middle ear effusion associated with tympanic membrane perforation. However, the degree of membrane perforation varied among those patients. Ear suppuration was prevented in all the patients with the drug; however, the perforated membranes of 9 patients $(52.9 \%)$ were healed. Among the 10 patients treated with calcarea sulphurica, ear suppuration was prevented in all patients. Calcarea sulphurica also healed perforated tympanic membranes of $50 \%$ of patients, however, Mercurius solubilis failed to trigger membrane healing in treating patients (Table. 3).

Table 3: Effect of homeopathic medicine in ear suppuration and healing of membrane perforation

\begin{tabular}{|c|c|c|c|c|c|}
\hline \multirow{2}{*}{$\begin{array}{c}\text { Homeopathic } \\
\text { medicines used for } \\
\text { treatment }\end{array}$} & \multirow[b]{2}{*}{$\begin{array}{c}\text { Total no. of } \\
\text { patients treated }\end{array}$} & \multicolumn{2}{|c|}{ Ear suppuration } & \multicolumn{2}{|c|}{$\begin{array}{c}\text { Tympanic membrane } \\
\text { perforation }\end{array}$} \\
\hline & & $\begin{array}{c}\text { Before } \\
\text { treatment }\end{array}$ & $\begin{array}{c}\text { Prevented } \\
\text { after } \\
\text { treatment }\end{array}$ & $\begin{array}{c}\text { Before } \\
\text { treatment }\end{array}$ & $\begin{array}{c}\text { Healed } \\
\text { after } \\
\text { treatment }\end{array}$ \\
\hline Tellurium metalicum & 17 & 17 & 17 & 17 & 9 \\
\hline Calcarea sulphurica & 10 & 10 & 10 & 10 & 5 \\
\hline Mercurius solubilis & 13 & 13 & 13 & 13 & 0 \\
\hline
\end{tabular}

The otoscopic view of three representative patients treated with Tellurium metallicum is shown in Figures 1, 2, and 3. In the first case, two distinct sites with perforations (indicated by white arrow) were visualized at the right tympanic membrane of the patient (Figure 1A). Healing of these perforations gradually occurred with time as the patient completed the course of the drug in 8 weeks (Figure 1B and C). In the second case, the pars flaccid portion of the tympanic membrane was associated with perforation (indicated with an arrow) and healing of the perforated membrane gradually occurred due to the intake of Tellurium metallicum (Figure 2B and C). The last case showed healing of the perforated pars flaccida of the tympanic membrane (Figure 3B and C).
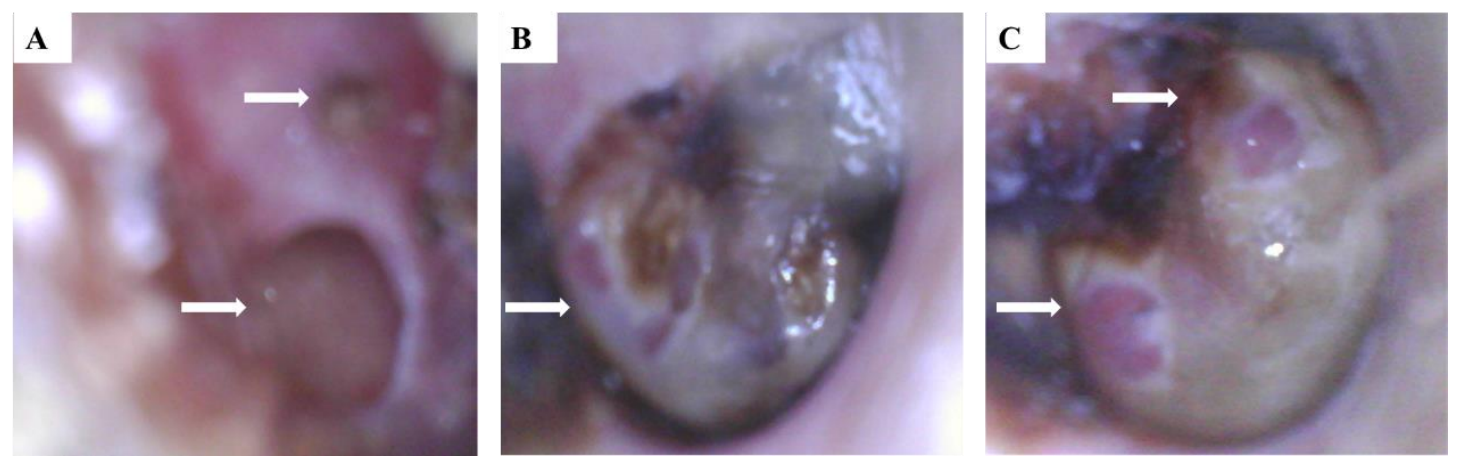

Figure 1. Healing of perforated tympanic membrane by Tellurium metallicum. Images of the tympanic membrane were captured before the treatment (A); after 4 weeks (B) and 8 weeks (C) of treatment. Aggregation of pus was observed (B).The cicatrized site is indicated with an arrow. 

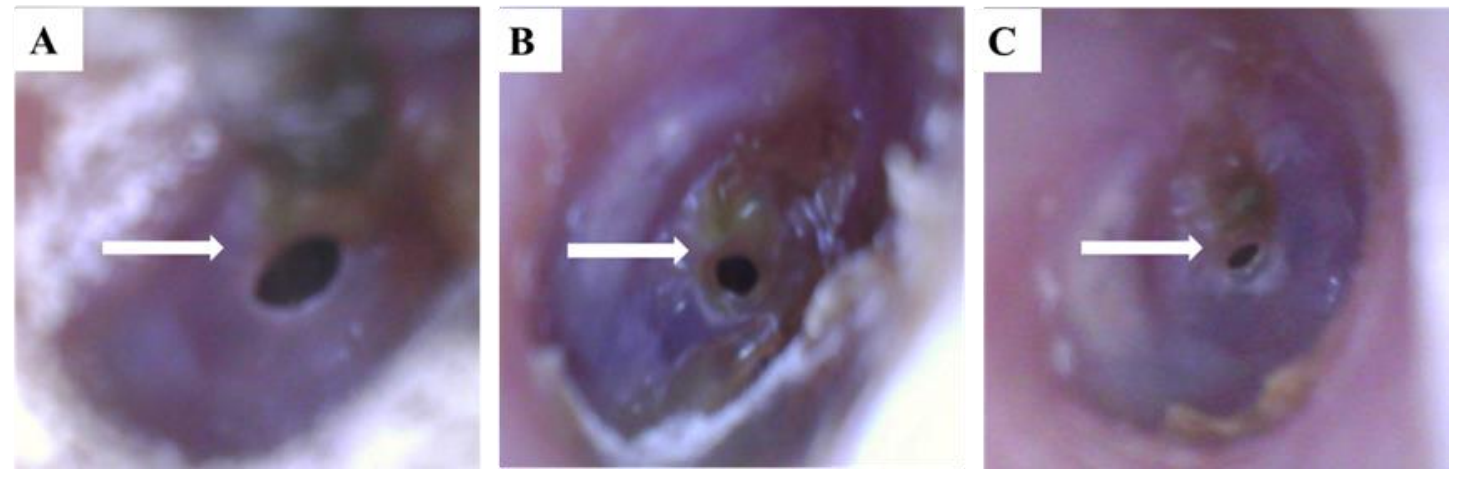

Figure 2. Gradual improvement of tympanic membrane perforation by tellurium metallicum. Otoscopic pictures showing tympanic membrane before treatment (A), after 4 weeks (B), and 8 weeks (C) treated by tellurium metallicum. The perforated site is indicated with an arrow.
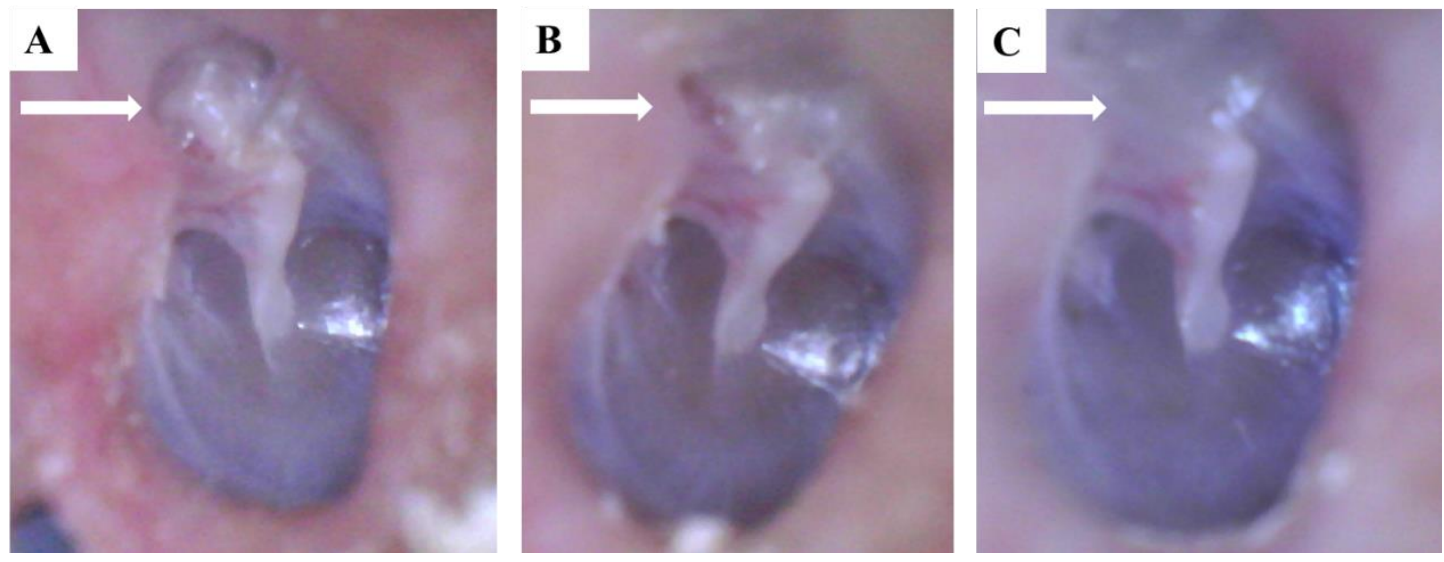

Figure 3. Healing of perforated 'Pars Flaccida' by tellurium metallicum. Using an endoscopic otoscope, pictures of the tympanic membrane were taken before initiating treatment (A). Follow-up images were taken at 4 weeks (B) and 8 weeks (C) of tellurium metallicum. Perforated 'Pars Flaccida' of the tympanic membrane is indicated with an arrow.

\section{CSOM patients underwent hearing impairment}

In most cases, CSOM patients experience hearing impairment due to inflammation in their middle ear. It was next examined whether the patients also underwent hearing impairment compared to healthy control subjects. The average hearing thresholds of the healthy control subjects $(n=30)$ at $1,4,8$, and $12 \mathrm{kHz}$ frequencies were $13.55 \pm 1.57,15.58 \pm 1.12,27.58 \pm$ 2.00, and $32.57 \pm 2.45 \mathrm{~dB}$ SPL, respectively (Figure 4A). On the other hand, the hearing threshold of the CSOM patients $(\mathrm{n}=40)$ who later underwent treatment were $30.25 \pm 1.75$, $36.80 \pm 3.25,50.75 \pm 2.35$, and $59.50 \pm 2.96 \mathrm{~dB}$ at $1,4,8$, and $12 \mathrm{kHz}$ frequencies, respectively. The threshold of hearing is known to be frequency-dependent. In this study, we observed an increase in mean hearing thresholds with increasing sound frequency in both cases of healthy control and CSOM patients. The hearing level is measured in $\mathrm{dB}$, and the values exceeding $20 \mathrm{~dB}$ at low frequencies (1 and $4 \mathrm{kHz}$ ) and the values exceeding $40 \mathrm{~dB}$ at high frequencies ( 8 and $12 \mathrm{kHz}$ ) indicate hearing impairment. Higher values of $\mathrm{dB}$ signify a higher degree of hearing impairment. Compared with the healthy controls, the average hearing thresholds of the CSOM patients at all the frequencies tested were significantly higher $(\mathrm{p}<0.05)$. These results suggest that the control subjects had better hearing overall, whereas the CSOM patients experienced a deterioration of hearing at all the frequencies tested.

The average hearing thresholds of the TM group patients $(n=17)$ before they started taking Tellurium metallicum at 1,4 ,
8 , and $12 \mathrm{kHz}$ frequencies were $31.91 \pm 2.11,41.32 \pm 2.43$, $54.85 \pm 2.51$, and $65 \pm 2.56 \mathrm{~dB}$ SPL, respectively. After eight weeks of Tellurium metallicum medication, the hearing thresholds at $1,4,8$, and $12 \mathrm{kHz}$ frequencies were found 17.94 $\pm 1.66,23.97 \pm 1.86,39.11 \pm 2.15$, and $44.70 \pm 2.25 \mathrm{~dB}$ SPL, respectively (Figure $4 \mathrm{~B}$ ). The hearing thresholds after 8 weeks of medication were significantly reduced $(p<0.05)$ at all the frequencies. This result indicated improvement of hearing thresholds by homeopathic medicine at all the frequencies tested. No significant change in hearing thresholds was observed in the patients (n-20) who received placebo doses instead of Tellurium metallicum. This result again confirms the effectiveness of Tellurium metallicum in improving hearing impairment.

In the case of MS group, the average hearing thresholds of the patients $(n=13)$ (before they started taking Mercurius solubilis) at $1,4,8$, and $12 \mathrm{kHz}$ frequencies were $32.11 \pm 1.24,41.15 \pm$ $1.34,52.88 \pm 0.80$, and $62.5 \pm 1.60 \mathrm{~dB}$ SPL, respectively (Figure 4C). After eight weeks of medication, the values of the hearing threshold became $14.80 \pm 1.16,21.53 \pm 1.52,34.42 \pm$ 1.12 , and $41.73 \pm 1.16 \mathrm{~dB}$ SPL, respectively. It was observed that Mercurius solubilis caused a significant reduction $(p<0.05)$ of the hearing thresholds at all the frequencies after 8 weeks of medication. No significant change in hearing thresholds was observed in the patients who received placebo doses instead of Mercurius solubilis. Similar results were obtained when Calcarea sulphurica (Figure 4D) was used for 
eight weeks in CS group patients $(\mathrm{n}=10)$. All of the above medicines significantly improved hearing thresholds in CSOM patients. These results are encouraging because CSOM- mediated hearing loss is treatable with homeopathic medicines cost-effectively.
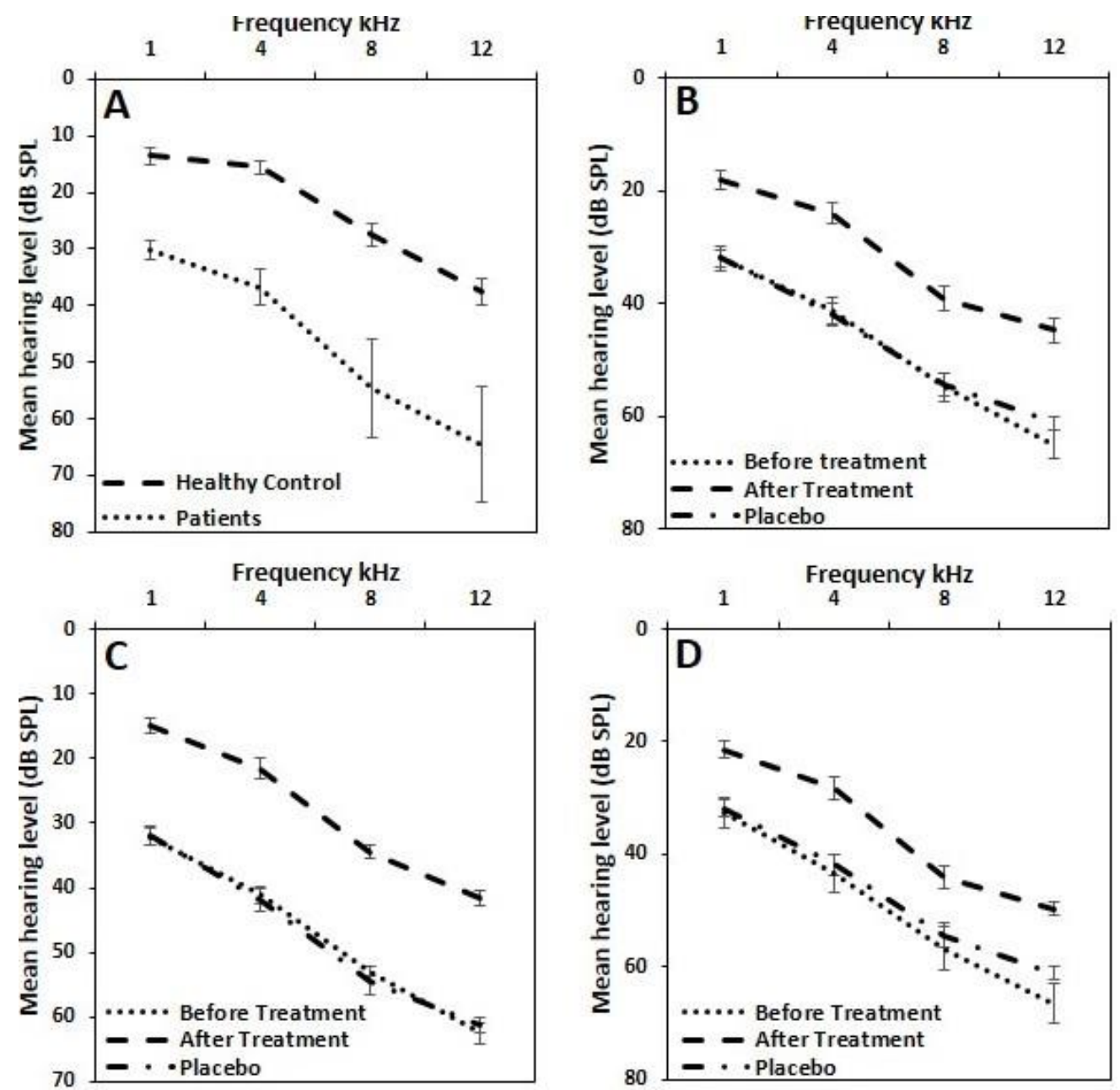

Figure 4. Homeopathic medicines TM, MS, and CS mediated improvement of hearing threshold. Average hearing thresholds (mean \pm SEM) of healthy control and CSOM patients without medication at 1, 4, 8, and $12 \mathrm{kHz}$ frequencies (A). Average hearing thresholds of CSOM patients before and after 8 weeks of TM (B), MS (C) and CS (D) medication together with placebo control.

\section{Discussion}

CSOM is usually a complication of persistent acute otitis media with perforation in the tympanic membrane. It is the commonest cause of mild to moderate hearing impairment in developing countries (Schilder et al., 2016), and the prevalence of this disease in Bangladesh is relatively high (Mahfuz et al., 2016; Kamal et al., 2004). The pathogenesis of otitis media has so far been studied well, and CSOM is generally treated with various antibiotics in combination or alone in different doses. Because of the emergence of antibiotic resistance and the potential risks of surgical treatment, treating CSOM now-a-days is becoming complicated. Besides, the effect of antibiotics is not mentionable in improving CSOM-related long-term complications such as hearing impairment and tympanic membrane perforation. Therefore, an urgent need to develop alternative treatment strategies against CSOM is evident.

For minimizing drug-related side effects, homeopathic remedies are sometimes preferred. While deciding a proper treatment, a homeopath examines various symptoms together with the patients' emotional issues and general physical shape. It is sometimes difficult to choose a proper remedy for a group of patients due to a lack of similar symptoms as well as responses to similar stimuli (Hahnemann, 1982). In this study, a set of common symptoms were analyzed and prescribed accordingly. CSOM patients with thin, pungent, or garlicky odorous pus, perforation of the tympanic membrane, and impaired hearing were treated with TM (Boericke, 2002; Murphy, 2003; Vermeulen, 1997; Hering, 1879). Patients having discharge of thick yellow pus, pain in the eustachian tube, and partial deafness were treated with MS (Boericke, 2002; Murphy, 2003; Vermeulen, 1997; Hering, 1879). CS was selected for CSOM with yellow or greenish-yellow lumpy pus, thin or thick long-lasting suppurative lesion, partial deafness with humming in the ear associated with the balance issues (Boericke, 2002; Murphy, 2003; Vermeulen, 1997; Hering, 1879).

Many previous studies have shown the use of homeopathic medicines in treating otitis media (Sinha et al., 2012; Frei and Thurneysen, 2001; Jacobs et al., 2001). However, the 
complicated symptoms in CSOM such as membrane perforation and hearing impairment were not addressed in most of the studies. Homeopathic medicines were applied in this study after observing an injury in the tympanic membrane with an aim to heal the ruptures. TM healed $52.9 \%$ and CS healed $50.0 \%$ perforated membranes in patients, however, MS was unable to show any effect in the healing process (Table-3; Figures 1-3). The degree of healing varied in our study might be due to the extent of perforation and other associated complications. The mechanisms of healing by these medicines are still unclear; however, the results are promising.

The complications of CSOM are considered more fatal when associated with hearing impairment (Moruskar et al., 2019). CSOM accompanied by a tympanic membrane perforation is coupled with hearing loss (Aneesa et al., 2019). The patients whose average pure-tone thresholds at 1 and $4 \mathrm{kHz}$ frequencies exceeded $20 \mathrm{~dB}$, and at 8 and $12 \mathrm{kHz}$ frequencies exceeded $40 \mathrm{~dB}$ were considered having hearing loss. The average pure-tone thresholds in the patients with perforated eardrums exceeded the above margin indicating a hearing loss in those patients. After 8 weeks of medication, all three medicines used in this study significantly reduced $(\mathrm{p}<0.05)$ hearing thresholds at all the frequencies tested. Hearing impairments in patients were thus proved to be improved by homeopathic medicine. Although the exact mechanism of hearing improvement is unknown presently, however, healing of the perforated tympanic membrane by the medications probably contributed well. Further study involving more participants is needed to clarify the mechanism of remedies by those medicines.

\section{Conclusion}

Improvement of hearing loss with cochlear implants or hearing aid devices is far beyond the reach of mass people. Cost-effective alternative treatment of CSOM would be well appreciated to control infections and related disorders. This study concludes that homeopathic medicines prevent ear suppuration in selected CSOM patients and heal the perforated tympanic membrane. These medicines also improved hearing thresholds in those treated patients. Although the mechanisms of these remedies are not clear yet, the results are very encouraging. We strongly believe that the results obtained in this study will act as a reference for effectively treating CSOM and related disorders.

\section{Acknowledgement}

We thank Dr. Masashi Kato, Professor and Chair, Department of Occupational and Environmental Health, Nagoya University Graduate School of Medicine, Japan for his generosity to provide us the iPod device for measuring hearing thresholds.

\section{References}

1. Arhus, L., Tambs, K., Kvestad, E. and Engdahl, B. 2015. Childhood otitis media: a cohort study with 30-year follow-up of hearing (the HUNT study). Ear and hearing, 36, 302.

2. Aneesa, M., Siraj, S. \& Ali, A. 2019. Correlation of tympanic membrane perforations with hearing loss. International
Journal of Otorhinolaryngology and Head and Neck Surgery, 5, 1213.

3. Antarasena, S., Antarasena, N., Lekagul, S. \& Lutadul, D. 1988. The epidemiology of deafness in Thailand. Otolaryngol Head Neck Surg, 3, 9-13.

4. Bastos, I. 1996. Otitis media and hearing loss among children in developing countries.

5. Boericke, W. 2002. Pocket Manual of Homoeopathic Materia Medica \& Repertory: Comprising of the Characteristic and Guiding Symptoms of All Remedies (clinical and Pahtogenetic [sic]) Including Indian Drugs, B. Jain publishers.

6. Das, A., Sumit, A. F., Ahsan, N., Kato, M., Ohgami, N. \& Akhand, A. A. 2018. Impairment of extra-high frequency auditory thresholds in subjects with elevated levels of fasting blood glucose. Journal of otology, 13, 29-35.

7. Fliss, D., Shoham, I., Leiberman, A. \& Dagan, R. 1991. Chronic suppurative otitis media without cholesteatoma in children in southern Israel: incidence and risk factors. The Pediatric infectious disease journal, 10, 895-899.

8. Frei, H. \& Thurneysen, A. 2001. Homeopathy in acute otitis media in children: treatment effect or spontaneous resolution? British Homoeopathic Journal, 90, 180-182.

9. Gehanno, P. \& Group, F. S. 1997. Multicenter study of the efficacy and safety of oral ciprofloxacin in the treatment of chronic suppurative otitis media in adults. OtolaryngologyHead and Neck Surgery, 117, 83-90.

10. Hahnemann, S. 1982. Organon of Medicine. Los Angeles: JP Tarcher. Inc.(Originally published 1810).

11. Hering, C. 1879. Guiding symptoms. Disponível no software Ecyclopaedia Homeopathica.

12. Jacob, A., Rupa, V., Job, A. \& Joseph, A. 1997. Hearing impairment and otitis media in a rural primary school in South India. International journal of pediatric otorhinolaryngology, 39, 133-138.

13. Jacobs, J., Springer, D. A. \& Crothers, D. 2001. Homeopathic treatment of acute otitis media in children: a preliminary randomized placebo-controlled trial. The Pediatric infectious disease journal, 20, 177-183.

14. Kamal, N., Joarder, A., Chowdhury, A. \& Khan, A. 2004. Prevalence of chronic suppurative otitis media among the children living in two selected slums of Dhaka City. Bangladesh Medical Research Council Bulletin, 30, 95-104.

15. Koch, A., Homøe, P., Pipper, C., Hjuler, T. \& Melbye, M. 2011. Chronic suppurative otitis media in a birth cohort of children in Greenland: population-based study of incidence and risk factors. The Pediatric infectious disease journal, 30, 25-29.

16. Lasisi, A. O., Olaniyan, F. A., Muibi, S. A., Azeez, I. A., Abdulwasiu, K. G., Lasisi, T. J., Imam, Z. O., Yekinni, T. O. \& Olayemi, O. 2007. Clinical and demographic risk factors associated with chronic suppurative otitis media. International journal of pediatric otorhinolaryngology, 71, 1549-1554.

17. Mahfuz, M. S. I., Kabir, A., Haq, A. Z., Chowdhury, A., Taous, A. \& Islam, M. M. 2016. Prevalence of Chronic Suppurative Otitis Media in Out Patient Department (OPD) in a District Level 250 Bedded General Hospital, Gopalganj, Bangladesh. Bangladesh Journal of Otorhinolaryngology, 22, 102-109.

18. Morris, P. 2012. Chronic suppurative otitis media. BMJ clinical evidence, 2012.

19. Moruskar, A., Karodpati, N., Ingale, M. \& Shah, S. 2019. Study of pattern of hearing loss in CSOM (chronic suppurative 
OTITIS media). Tropical Journal of Opthalmology and Otolaryngology, 4, 131-136.

20. Murphy, R. 2003. Lotus materia medica, B. Jain Publishers.

21. Muya, E. W. \& Owino, O. 1986. Special education in Africa: research abstracts, UNESCO.

22. Schilder, A. G., Chonmaitree, T., Cripps, A. W., Rosenfeld, R. M., Casselbrant, M. L., Haggard, M. P. \& Venekamp, R. P. 2016. Otitis media. Nature Reviews Disease Primers, 2, 16063.

23. Schilder, A. G., Marom, T., Bhutta, M. F., Casselbrant, M. L., Coates, H., Gisselsson-Solén, M., Hall, A. J., Marchisio, P., Ruohola, A. \& Venekamp, R. P. 2017. Panel 7: otitis media: treatment and complications. Otolaryngology-Head and Neck Surgery, 156, S88-S105.

24. Seely, D. R., Gloyd, S. S., Wright, A. D. O. \& Norton, S. J. 1995. Hearing loss prevalence and risk factors among Sierra Leonean children. Archives of Otolaryngology-Head \& Neck Surgery, 121, 853-858.

25. Sinha, M., Siddiqui, V., Nayak, C., Singh, V., Dixit, R., Dewan, D. \& Mishra, A. 2012. Randomized controlled pilot study to compare Homeopathy and Conventional therapy in Acute Otitis Media. Homeopathy, 101, 5-12.

26. Sinkkonen, S., Jero, J. \& Aarnisalo, A. 2014. Tympanic membrane perforation. Duodecim; laaketieteellinen aikakauskirja, 130, 810-818.
27. Smith, L., Ewings, P., Smith, C., Thompson, M., Harnden, A. \& Mant, D. 2010. Ear discharge in children presenting with acute otitis media: observational study from UK general practice. Br J Gen Pract, 60, 101-105.

28. Sumit, A. F., Das, A., Sharmin, Z., Ahsan, N., Ohgami, N., Kato, M. \& Akhand, A. A. 2015. Cigarette smoking causes hearing impairment among Bangladeshi population. PloS one, 10, e0118960.

29. Talukder, M. H. A. R., Hossain, M. M., Islam, M. T., Ali, M. I., Rahman, M. \& Haque, M. M. 2016. Frequency of extracranial complications of chronic suppurative otitis media. Journal of Bangladesh College of Physicians and Surgeons, 34, 3-8.

30. Vermeulen, F. E. 1997. Concordant Materia Medica: Allen, Boericke, Boger, Cowperthwaite, Clarke, Hering, Kent, Lippe, Puhatak, Pulford, Vermeulen: Hering Included, Emryss bv.

31. Williams, D. J. \& Noyes, J. M. 2007. How does our perception of risk influence decision-making? Implications for the design of risk information. Theoretical issues in ergonomics science, 8, 1-35.

32. Zahnert, T. 2011. The differential diagnosis of hearing loss. Deutsches ärzteblatt international, 108, 433. 